\title{
More Than Charged Base Loss - Revisiting the Fragmentation of Highly Charged Oligonucleotides
}

\author{
Adrien Nyakas, Rahel P. Eberle, Silvan R. Stucki, Stefan Schürch
}

Department of Chemistry and Biochemistry, University of Bern, Bern, Switzerland

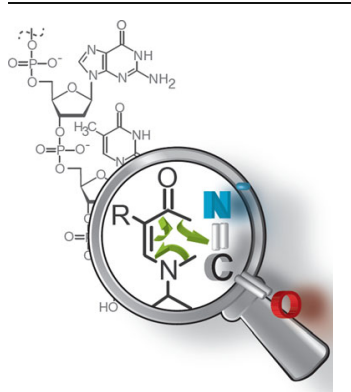

\begin{abstract}
Tandem mass spectrometry is a well-established analytical tool for rapid and reliable characterization of oligonucleotides (ONs) and their gas-phase dissociation channels. The fragmentation mechanisms of native and modified nucleic acids upon different mass spectrometric activation techniques have been studied extensively, resulting in a comprehensive catalogue of backbone fragments. In this study, the fragmentation behavior of highly charged oligodeoxynucleotides (ODNs) comprising up to 15 nucleobases was investigated. It was found that ODNs exhibiting a charge level (ratio of the actual to the total possible charge) of $100 \%$ follow significantly altered dissociation pathways compared with low or medium charge levels if a terminal pyrimidine base ( $3^{\prime}$ or
\end{abstract} $\left.5^{\prime}\right)$ is present. The corresponding product ion spectra gave evidence for the extensive loss of a cyanate anion ( $\left.\mathrm{NCO}^{-}\right)$, which frequently coincided with the abstraction of water from the $3^{\prime}$ - and $5^{\prime}$-end in the presence of a 3'- and 5'-terminal pyrimidine nucleobase, respectively. Subsequent fragmentation of the $\mathrm{M}$ $\mathrm{NCO}^{-}$ion by $\mathrm{MS}^{3}$ revealed a so far unreported consecutive excision of a metaphosphate $\left(\mathrm{PO}_{3}{ }^{-}\right)$-ion for the investigated sequences. Introduction of a phosphorothioate group allowed pinpointing of $\mathrm{PO}_{3}{ }^{-}$loss to the ultimate phosphate group. Several dissociation mechanisms for the release of $\mathrm{NCO}^{-}$and a metaphosphate ion were proposed and the validity of each mechanism was evaluated by the analysis of backbone- or sugarmodified ONs.

Keywords: Oligonucleotides, Tandem mass spectrometry, Fragmentation, CID, Nucleic acids, Dissociation mechanism, Modified oligonucleotides

Received: 14 November 2013/Revised: 30 January 2014/Accepted: 28 February 2014/Published online: 7 May 2014

\section{Introduction}

$\mathrm{T}$ andem mass spectrometry (MS/MS) is a wellestablished analytical tool in oligonucleotide research, attributable to its little demands in sample amounts, tolerance towards structural modifications, as well as speed of analysis. In the last decade, the elucidation of gas-phase fragmentation mechanisms has evolved to one of the main pillars of mass spectrometry-based oligonucleotide research. Applying an array of different dissociation techniques, the fragmentation of DNA [1-4], RNA [5-8], and modified oligonucleotides [8-14] has been investigated in great detail, resulting in a comprehensive catalogue of prominent

Adrien Nyakas and Rahel P. Eberle contributed equally to this project.

Electronic supplementary material The online version of this article (doi:10.1007/s13361-014-0873-4) contains supplementary material, which is available to authorized users.

Correspondence to: Stefan Schürch; e-mail: stefan.schuerch@dcb.unibe.ch dissociation pathways oligonucleotides follow in the gasphase.

Commonly, either hydrogen/deuterium exchange (HDX) experiments have been performed $[3,7]$ or chemical modifications were introduced $[6,8,13-15]$ to elucidate if exchangeable protons are involved in the fragmentation cascade or to specifically inactivate proton donor sites, respectively. As a result, precise information about the dissociation channels of nucleic acids were obtained, which facilitated the interpretation of tandem mass spectra of DNA and RNA in general, as well as the development of software tools for the automated calculation of theoretical fragment ion masses and subsequent matching of those with experimental results [16-19].

However, not only the influence of structural modifications on the generated product ion pattern was investigated but also the influence of different precursor ion charge states. In 1993, McLuckey et al. [2] found that for highly charged precursor ions loss of a charged nucleobase is the main event, with the following order of preference: $\mathrm{A}^{-}>\mathrm{T}^{-}$ $>\mathrm{G}^{-}>\mathrm{C}^{-}$. Neutral base loss was only observed for lower 
charge states, which led to the conclusion that the main driving force for charged base loss (CBL) is most likely the relief of Coulombic strain.

Pan et al. introduced the term "charge level" (CL), which is the ratio of the actual charge state to the total number of phosphate groups within the ON [20]. They investigated the influence of the precursor ion charge on the fragmentation of oligonucleotides and also found that higher CLs $(>50 \%)$ facilitate loss of a charged nucleobase over neutral base loss, with a strong preference for abstraction of an adenine anion. They subsequently calculated the electrostatic potential surface for all nucleobases, which revealed that $\mathrm{A}^{-}$represents the most stabilized anion, attributable to the strongest delocalization of the negative charge in the aromatic ring structure.

In 2008, McLuckey and co-workers studied the gas-phase fragmentation of deprotonated RNA and DNA dinucleotides as well as an RNA 8-mer (GCGGAUUU) [21]. They investigated the octamer in different charge states and applied different excitation levels, which resulted in an increased loss of adenine and a more pronounced generation of a-B-/w-ion pairs. $\mathrm{MS}^{2}$ and pseudo-MS ${ }^{3}$ experiments of the RNA dinucleotides $(\mathrm{GpC}, \mathrm{CpU}, \mathrm{GpU}, \mathrm{UpU})$ were performed to rationalize the relative intensities of the product ions formed upon collision induced dissociation (CID) of the RNA octamer. In each product ion spectrum of the dinucleotide anions (DNA and RNA) loss of isocyanic acid $\left(\left[\mathrm{M}^{-}-\mathrm{HNCO}\right]^{-}\right)$was observed, even though in low abundance only and when applying high excitation amplitudes. It was found that pyrimidine bases preferentially release a HNCO neutral, whereas for purine bases, rather loss of $\mathrm{HCN}$ is observed. However, the product ion spectrum of the RNA octamer (GCGGAUUU) did not show a signal for isocyanate loss regardless of the charge level and the applied energy.

Loss of $\mathrm{HNCO}$ has been frequently observed upon fragmentation of the free pyrimidine nucleobases thymine (T), uracil (U), and cytosine (C), irrespective of the applied dissociation technique and the polarity of the MS acquisition [22-27]. Rice et al. were the first to describe the loss of isocyanic acid $(\mathrm{H}-\mathrm{N}=\mathrm{C}=\mathrm{O})$ upon EI-MS of pyrimidine derivatives [22]. They stated that the $\left[\mathrm{M}^{-}-\mathrm{HNCO}\right]^{-}$signal is the result of a concerted Retro-Diels-Alder (RDA) reaction, since no evidence for ring opening prior to HNCO expulsion was observed. As of then, loss of HNCO from pyrimidine nucleobases has been rationalized by an RDA mechanism almost exclusively [27-31]. It was further postulated by Rice et al. that always the $\mathrm{C} 2$ and $\mathrm{N} 3$ atoms of uracil, thymine, and cytosine are involved in the abstraction of $\mathrm{HNCO}$ [22], which was later proven by means of HDX, introduction of structural modifications, as well as computational methods [27, 32-34]. Furthermore, Guillaumont et al. found evidence that the frequently observed carbon monoxide (CO) loss solely occurs at the $\mathrm{C} 4$ atom of $\mathrm{U}$ and $\mathrm{T}$ [32].

Nelson and McCloskey investigated the product ions generated upon CID of protonated uracil and several of its derivatives [27]. Abstraction of HNCO was the principal dissociation channel for all investigated nucleobases, besides the loss of $\mathrm{H}_{2} \mathrm{O}, \mathrm{NH}_{3}$, and $\mathrm{CO}$, as well as the minor product ions $\left[\mathrm{M}^{+}-\mathrm{HNCO}-\mathrm{HCN}\right]^{+},\left[\mathrm{M}^{+}-\mathrm{H}_{2} \mathrm{O}-\mathrm{CO}-\mathrm{HCN}\right]^{+}$and $\left[\mathrm{M}^{+}-\right.$ $\left.\mathrm{C}_{3} \mathrm{H}_{3} \mathrm{NO}\right]^{+}$. In most studies, the fragmentation of pyrimidine nucleobases, nucleosides, and nucleotides was examined in the positive ion mode, which always yielded a strong signal for $\left[\mathrm{M}^{+}-\mathrm{HNCO}\right]^{+}[23,27,28,34-36]$. In the negative ion mode, also intense signals for $\left[\mathrm{M}^{-}-\mathrm{HNCO}\right]^{-}$were observed but, additionally, a strong peak of the cyanate anion $\left(\mathrm{NCO}^{-}\right.$, $\mathrm{m} / \mathrm{z} 42$ ) was detected $[30,35]$. Ingólfsson and co-workers demonstrated with post-source decay (PSD) experiments and classic dynamics simulation methods that $\mathrm{NCO}^{-}$generation solely proceeds via deprotonation at the N3 position of the pyrimidine base, which in turn triggers the RDA mechanism $[24,30]$.

However, Improta et al. showed with density functional methods that for radical thymine cations, the process of $\mathrm{HNCO}$ and $\mathrm{NCO}^{-}$loss is not strictly concerted and, thus, probably not a conventional RDA reaction [36]. For cyanate loss upon dissociative electron attachment (DEA), Almeida et al. also proposed a multi-step process in which deprotonation of the nucleobase is the result of initial electron capture and results in considerable bond stretching and subsequent $\mathrm{NCO}^{-}$loss [25]. Recently, da Silva et al. agreed with this decomposition process and stated that this complex, unimolecular reaction sequence, which includes cleavage of two covalent bonds of the ring structure, is likely to occur on a longer time scale than initially believed [37]. Yet, all the applied fragmentation techniques [25, 36, 37] are based on calculations and observations of oddelectron species and, thus, potentially differ from dissociation processes in even-electron precursor ions as in CID or PSD experiments.

In general, loss of $\mathrm{HNCO}, \mathrm{NCO}^{-}$, or the cyanate anion were only observed for isolated nucleobases, nucleosides, and (di)nucleotides, but never for oligonucleotides comprising more than two nucleobases. Hence, it was assumed that loss of isocyanic acid is a prevalent dissociation event for small nucleic acid units only [38].

Herein, we present a comprehensive study about the extensive loss of $\mathrm{NCO}^{-}$from highly charged oligonucleotides and the subsequent excision of the terminal phosphate group upon CID. Only recently, $\mathrm{NCO}^{-}$was announced as a key fragment upon DEA and electron transfer to pyrimidine bases [37]. However, $\mathrm{NCO}^{-}$formation upon CID of highly charged DNA oligomers constitutes a new addition to the large catalogue of potential product ions of oligonucleotides and, hence, it is of major interest to elucidate the prerequisites that open this highly specific fragmentation channel. In this study, the underlying dissociation mechanisms were investigated step-by-step by selectively incorporating structural modifications and adjusting the base composition of model ONs, in order to gradually unravel each fragmentation step. Hence, we report an in-depth analysis of the principal fragmentation pathways of oligo- 
nucleotides exhibiting a charge level of $80 \%-100 \%$ as well as a $3^{\prime}$ - or $5{ }^{\prime}$-terminal pyrimidine nucleobase.

\section{Experimental}

\section{Oligonucleotides, Chemicals, and Solvents}

The unmodified oligodeoxynucleotides were purchased from Microsynth (Balgach, Switzerland), the methylphosphonate oligodeoxynucleotides were synthetized by Eurogentec S.A. (Seraing, Belgium) and TriLink (San Diego, California, USA), who also provided the oligoribonucleotides, the phosphorothioate deoxynucleotides, as well as the dideoxyoligonucleotide. The homoDNA oligonucleotides were synthesized according to the previously published procedure [39]. All oligonucleotides were used without further purification and rehydrated in Fluka HPLC water to yield a concentration of $1 \mathrm{nmol} / \mu \mathrm{L}$. Prior to MS analysis, the oligodeoxynucleotides were diluted with methanol until a 50\% $\mathrm{MeOH}$ solution with an oligonucleotide concentration of 10 $20 \mathrm{pmol} / \mu \mathrm{L}$ was obtained. The oligoribonucleotides were diluted in acetonitrile:water: triethylamine (49:49:2) solution to the same concentration of $10-20 \mathrm{pmol} / \mu \mathrm{L}$.

\section{Electrospray Ionization Mass Spectrometry (ESI-MS)}

ESI-MS experiments were performed on a LTQ Orbitrap XL mass spectrometer (Thermo Fisher Scientific, Bremen, Germany), equipped with a nano-electrospray ion source. Experiments were carried out in the negative ion mode with potentials of $-650 \mathrm{~V}$ to $-850 \mathrm{~V}$ applied to the nanoelectrospray needle. Mass spectra were acquired in the FTMS mode from $\mathrm{m} / \mathrm{z} 150$ to 2000 with the mass resolution set to 100,000 . The source conditions were chosen as follows: capillary temperature $150^{\circ} \mathrm{C}$, capillary voltage $-8 \mathrm{~V}$, tube lens voltage $-8 \mathrm{~V}$. For collision-induced dissociation in the linear ion trap, precursor ions were selected within a window of $\pm 2.5 \mathrm{~m} / \mathrm{z}$ units, and relative collision energies (RCE) in the range from $15 \%$ to $30 \%$ were applied. The activation time was $100 \mathrm{~ms}$ and helium was used as the collision gas. The Xcalibur Software Suite including Qualbrowser version 2.0.7 (Thermo Fisher Scientific) was used for data processing. Peak assignment was supported by the OMA \& OPA software tool [18].

\section{Results and Discussion}

\section{Gas-Phase Fragmentation of Highly Charged Oligodeoxynucleotides}

When investigating the charge state dependent gas phase fragmentation of the DNA hexamer GATCGT (\#1, Table 1) by nanoESI MS/MS, an intense peak at $\mathrm{m} / z$ 439.8264, not corresponding to a standard backbone fragment ion or base loss ion, was generated if the completely deprotonated precursor ion was subjected to CID (if not stated otherwise all $\mathrm{m} / \mathrm{z}$ values represent accurate masses). The loss of $42.0004 \mathrm{Da}$ and a negative charge from the precursor ion could be attributed to the abstraction of a cyanate anion $\left(\mathrm{NCO}^{-}\right)$, which is known to be one of the main product ions upon MS/MS of pyrimidine bases, nucleosides, and nucleotides (Figure 1).

Proof was obtained by comparing the calculated and

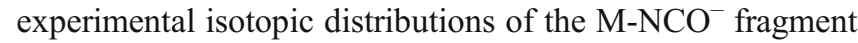
of GATCGT, which represents a perfect fit for cyanate loss with a mass accuracy of $0.46 \mathrm{ppm}$ (Supplemental Figure 1a). This is remarkable in that to the best of our knowledge cyanate loss was not observed upon CID of oligonucleotides longer than 2-mers so far. The excess of negative charge apparently promotes new dissociation pathways that not only include backbone cleavage or CBL but also compromise the structural integrity of the nucleobases.

To obtain more information about cyanate loss, three additional hexameric sequences were investigated: AGTCGA (\#2), ACGTCA (\#3), and TCGTCA (\#4). In contrast to \#1 and $\# 4$, compounds \#2 and \#3 did not yield a $\mathrm{M}^{-\mathrm{NCO}^{-}}$fragment irrespective of the investigated charge state even though both ONs comprise pyrimidine nucleobases. As the main difference between these sequences is the presence of a terminal thymine in \#1 and \#4 in contrast to an "internal" thymine in \#2 and \#3, $\mathrm{NCO}^{-}$loss was likely to occur at the ultimate nucleobase. To validate this assumption, $\mathrm{MS}^{3}$ spectra of the $\mathrm{M}^{-\mathrm{NCO}^{-}}$ions of GATCGT (\#1) and TCGTCA (\#4) were acquired (Figure 2). Detection of distinct fragment ions (marked in red) allowed for unambiguous identification of the terminal thymine as the source of cyanate loss.

To determine the influence of the nucleic acid composition and oligonucleotide length on cyanate loss, additional DNA sequences were examined. The investigated ONs, the highest isolated charge level, as well as the intensity of the corresponding $\mathrm{NCO}^{-}$loss are summarized in Table 1. The relative intensity of cyanate abstraction was calculated with respect to the 25 most abundant peaks in the product ion spectra (TOP 25). Since loss of $\mathrm{NCO}^{-}$was observed in connection with other dissociation channels, such as base or water loss, the relative intensity of these product ions was considered as well. The ONs marked with an asterisk also exhibited $\mathrm{NCO}^{-}$loss, but not among the 25 peaks of highest intensity. The specific relative intensity of the ${\mathrm{M}-\mathrm{NCO}^{-}}^{-}$signal is given in parenthesis.

Table 1 clearly shows that both sequence length and nucleic acid composition play a crucial role in the process of cyanate loss. It was found that the tendency for prominent cyanate abstraction decreases with increasing sequence length. The completely deprotonated precursor ion $(100 \%$ $\mathrm{CL}$ ) could be isolated for oligonucleotides comprising up to eight nucleobases, all of which exhibited cyanate abstraction within the TOP 25 peaks. However, the overall tendency of $\mathrm{NCO}^{-}$release decreases considerably with longer oligonucleotides, as there is stronger competition with the $\mathrm{CBL}$ dissociation channel as well as more pronounced generation of backbone fragments. Also, formation of the fully deprotonated precursor ion becomes more difficult with increasing chain length, so that the observation of marginal 
Table 1. Investigated DNA and RNA Oligonucleotide Sequences. Sequences Marked with an Asterisk also Exhibit NCO ${ }^{-}$Loss, however, not within the TOP 25 Peaks

\begin{tabular}{|c|c|c|c|c|c|}
\hline & \# & Sequence & $\# \mathrm{nt}$ & Max. charge level & Rel. int. $\mathrm{NCO}^{-}$loss \\
\hline \multirow{22}{*}{ DNA } & 1 & GATCGT & 6 & $100 \%$ & $34 \%$ \\
\hline & 2 & AGTCGA & 6 & $100 \%$ & $0 \%$ \\
\hline & 3 & ACGTCA & 6 & $100 \%$ & $0 \%$ \\
\hline & 4 & TCGTCA & 6 & $100 \%$ & $16 \%$ \\
\hline & 5 & ACTGCC* & 6 & $100 \%$ & $0 \%(0.08 \%)$ \\
\hline & 6 & AGAGCT & 6 & $100 \%$ & $15 \%$ \\
\hline & 7 & TGCTGC & 6 & $100 \%$ & $62 \%$ \\
\hline & 8 & TGCACT & 6 & $100 \%$ & $8 \%$ \\
\hline & 9 & CCGGTT & 6 & $100 \%$ & $48 \%$ \\
\hline & 10 & TTGACG & 6 & $100 \%$ & $2 \%$ \\
\hline & 11 & CCGTCA* & 6 & $100 \%$ & $0 \%(0.21 \%)$ \\
\hline & 12 & CCGTAA* & 6 & $100 \%$ & $0 \%(0.17 \%)$ \\
\hline & 13 & ATAGGC* & 6 & $100 \%$ & $0 \%(0.08 \%)$ \\
\hline & 14 & CGTAGTT & 7 & $100 \%$ & $4 \%$ \\
\hline & 15 & AGTCGTT & 7 & $100 \%$ & $5 \%$ \\
\hline & 16 & CGTAGATT & 8 & $100 \%$ & $1 \%$ \\
\hline & 17 & TCATGAGT & 8 & $100 \%$ & $2 \%$ \\
\hline & 18 & CGTACGATT* & 9 & $87.5 \%$ & $0 \%(7.64 \%)$ \\
\hline & 19 & CCGGCTGGTT & 10 & $66,67 \%$ & $3 \%$ \\
\hline & 20 & ATATGTACATAT* $*$ & 12 & $72.73 \%$ & $0 \%(6.07 \%)$ \\
\hline & 21 & ACTGGTCACTAT* & 12 & $72.73 \%$ & $0 \%(0.42 \%)$ \\
\hline & 22 & TATAACCAATATAAT & 15 & $50 \%$ & $0 \%$ \\
\hline \multirow[t]{6}{*}{ RNA } & 23 & CGGCUU & 6 & $100 \%$ & $77 \%$ \\
\hline & 24 & CCGGUU & 6 & $100 \%$ & $71 \%$ \\
\hline & 25 & CCUGGU & 6 & $100 \%$ & $72 \%$ \\
\hline & 26 & GAUCGU & 6 & $100 \%$ & $74 \%$ \\
\hline & 27 & UGCUAG & 6 & $100 \%$ & $2 \%$ \\
\hline & 28 & GAUCGC* & 6 & $100 \%$ & $0 \%(2.95 \%)$ \\
\hline
\end{tabular}

(a)

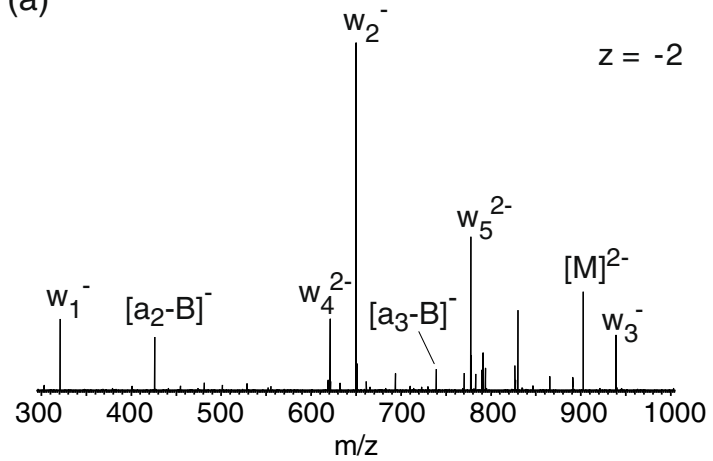

(c)

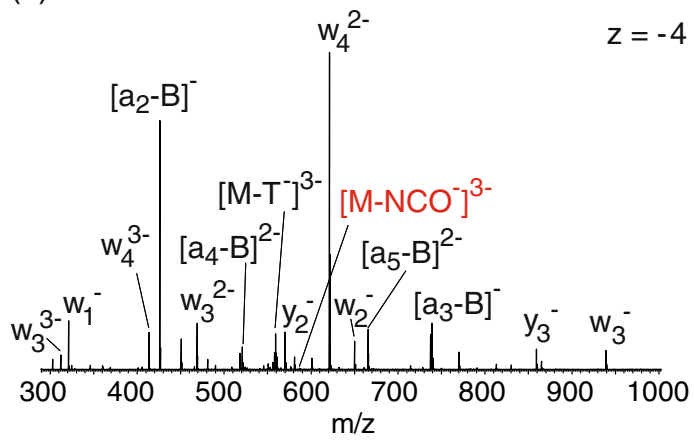

(b)

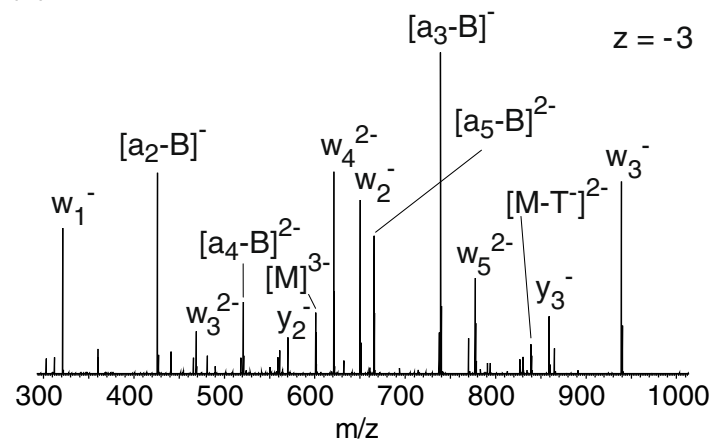

(d)

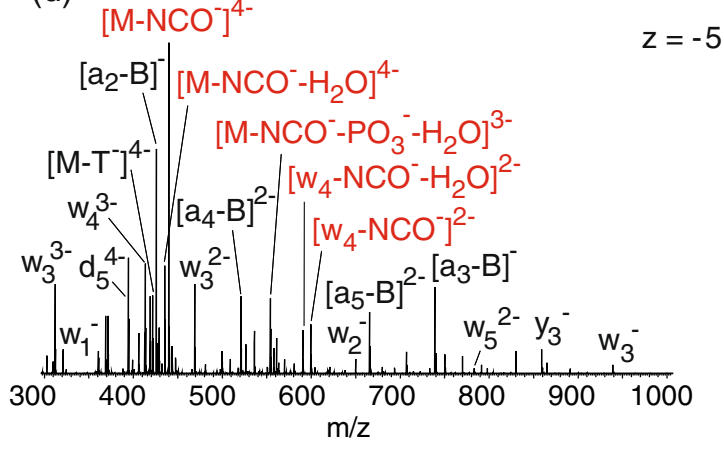

Figure 1. Charge state-dependent fragmentation of the DNA hexamer GATCGT (\#1). Intensive loss of NCO- is observed when precursor ions exhibiting a charge level of $100 \%$ are fragmented. [RCE: (a), (d) $15 \%$, (b), (c) $20 \%$ ] 
(a)

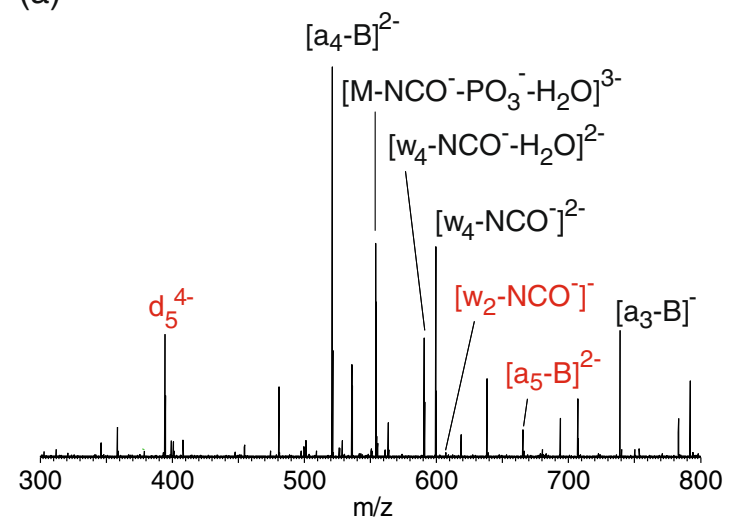

(b)

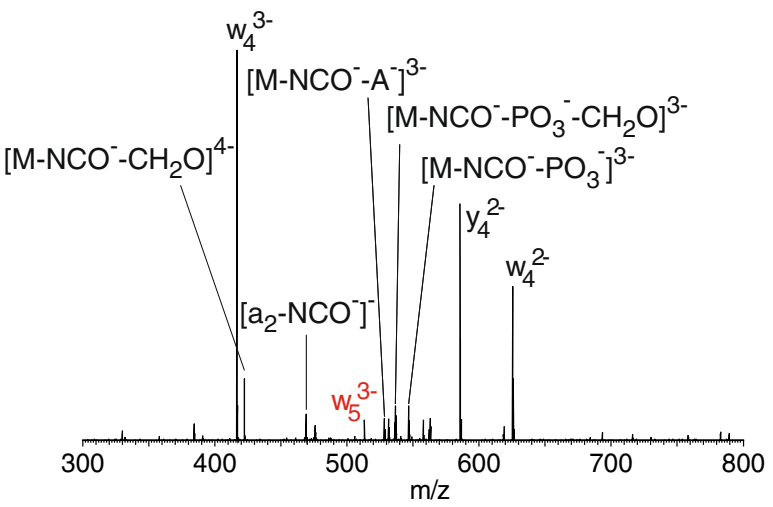

Figure 2. $\mathrm{MS}^{3}$ spectra of $\left[\mathrm{M}-\mathrm{NCO}^{-}\right]^{4-}$ of GATCGT (a) and TCGTCA (b). Detection of $\mathrm{d}_{5^{-}}\left(\mathrm{m} / \mathrm{z}\right.$ 394.5582) and $\mathrm{w}_{5}$-ions $(\mathrm{m} / \mathrm{z}$ 513.0792) gives evidence for terminal $\mathrm{NCO}^{-}$loss from the sequences GATCGT (\#1) and TCGTCA (\#4), respectively. [RCE: (a) $20 \%$, (b) $30 \%]$

$\mathrm{NCO}^{-}$loss for ONs larger than 9-mer is probably mostly due to an insufficient charge level of less than $100 \%$.

Furthermore, loss of $\mathrm{NCO}^{-}$was found to be more facile for ONs exhibiting a terminal thymine instead of a cytosine or a pyrimidine base that is located at the 3 '-end instead of the 5'-end. The latter is evident comparing the relative intensities of cyanate loss among the TOP 25 peaks of the sequences \#1 (3'-terminal $\mathrm{T})$ and \#4 (5'-terminal $\mathrm{T})$ that account for $34 \%$ and $16 \%$, respectively, even though the remaining nucleobase composition is almost identical. Cyanate loss from terminal cytosines was found to be generally very low abundant and in contrast to terminal thymine, a charge state-dependent increase of cytosine decomposition was not observed. For the sequences CCGTCA (\#11) and CCGTAA (\#12), the relative intensity of the $\mathrm{M}-\mathrm{NCO}^{-}$peak was principally around $1 \%$ and did not change when increasing the $\mathrm{CL}$ from $60 \%(\mathrm{z}=-3)$ to $100 \%$ $(z=-5)$. ACTGCC (\#5) and ATAGGC (\#13) could only be fragmented in their 4- and 5-fold negatively charged form, but confirmed the previous finding by generally yielding a $\mathrm{NCO}^{-}$loss of less than $1 \%$ relative intensity for both charge levels. Thus, loss of a cyanate anion from terminal cytosines is in comparison a rather unspecific, minor dissociation event, observed irrespective of the precursor ion charge state of the oligonucleotide. After analysis of all product ion spectra, it is intriguing though, that no evidence for $\mathrm{NCO}^{-}$ loss from an internal pyrimidine position was found.

As reflected by Table 1, it is evident that very high charge levels (>90\%) trigger the release of a cyanate anion from terminal thymines. Hence, as for CBL, cyanate loss can be considered as a form of charge-reduction to decrease Coulombic strain in the ON. The "terminal effect" has so far not been reported in literature, but the distinct conditions upon which such dissociation pathway is observed suggest that electronic and steric factors are involved. A possible explanation is based on a study of Anusiewicz et al., who performed molecular dynamics simulations on a DNA 5-mer $\left(\mathrm{T}_{5}{ }^{3-}\right)$ with zero and three negative charges on the backbone to investigate the effect of increased Coulombic repulsion on the gas-phase structure [40]. It was shown that a 3-fold negatively charged pentamer is likely to adopt an elongated, stretched configuration, whereas the same $\mathrm{ON}$ with a neutral backbone is arranged in a rather compact structure. It was also stated that due to dynamical fluctuations, there are periods where the 3 -fold negatively charged $\mathrm{ON}$ is also in a more scrambled shape, but that in the gas-phase the extended structure is certainly the preferred one.

Since the ONs investigated in this study exhibit a fully deprotonated backbone, one can assume that due to higher Coulombic repulsion among the phosphate groups, the gasphase structure is particularly rigid. Consequently, it is highly probable that the ONs in this study show an even stronger lack in flexibility and are, thus, predominantly found in an extended structure. As higher electrostatic repulsion potentially impacts standard dissociation pathways in highly charged ONs, alternative dissociation channels, such as pyrimidine base fragmentation, might be activated. But for all investigated ONs with a CL of $100 \%$, release of a cyanate anion always coincided with charged base loss and the generation of "classic" product ions belonging to the a-B- and $\mathrm{w}$-ion series. The latter, however, partially resulted from backbone fragmentation after loss of $\mathrm{NCO}^{-}$, as proven by standard DNA fragments lacking the mass of a cyanate anion $\left(\mathrm{w}_{4}-\mathrm{NCO}^{-}\right.$, a-B$\mathrm{NCO}^{-}$). This suggests that the cyanate dissociation channel proceeds on a rather small time scale, but also that ONs with a CL of $100 \%$ still exhibit a minimum degree of flexibility as regularly standard product ions with uncompromised structural integrity were detected.

\section{Mechanistic Aspects of Cyanate Loss}

Only recently $\mathrm{NCO}^{-}$release has been reported as a RDA reaction triggered by deprotonation of the nucleobase [30, $33,37]$. However, activation of the $\mathrm{NCO}^{-}$pathway might be different in DNA hexamers than for the isolated nucleobase 
or nucleoside, especially since the prerequisites for cyanate loss have been found to be very specific for longer sequences.

We propose three different dissociation mechanisms (Scheme 1) for the release of $\mathrm{NCO}^{-}$upon CID of highly negatively charged oligonucleotides, representatively using thymine as a model base. The feasibility of the pathways was investigated by analyzing structurally modified analogues of the sequence CCGGTT (\#9). Customized introduction of structural alterations allowed specific inhibition of certain proton transfer reactions to either confirm or contradict the postulated dissociation channels. Loss of water has been included in each mechanism, as it is the major concomitant dissociation pathway of cyanate loss (Supplemental Figure 1b). CCGGTT shows a considerable loss of $\mathrm{NCO}^{-}$when fragmenting the 5-fold negatively charged precursor ion $(\mathrm{m} / \mathrm{z}$ 355.4592) (Supplemental Figure 2a). Furthermore, the $M^{3}{ }^{3}$ spectrum of [CCGGTT-NCO $]^{4-}$ (Supplemental Figure $2 \mathrm{~b}$ ) agrees well with the previously drawn conclusion that $\mathrm{NCO}^{-}$ release from 5 '-terminal cytosines is a rather minor event, since the detected 5'-terminal fragments are almost exclusively structurally intact, whereas all product ions originating from the 3 '-side exhibit additional $\mathrm{NCO}^{-}$loss.

(a)
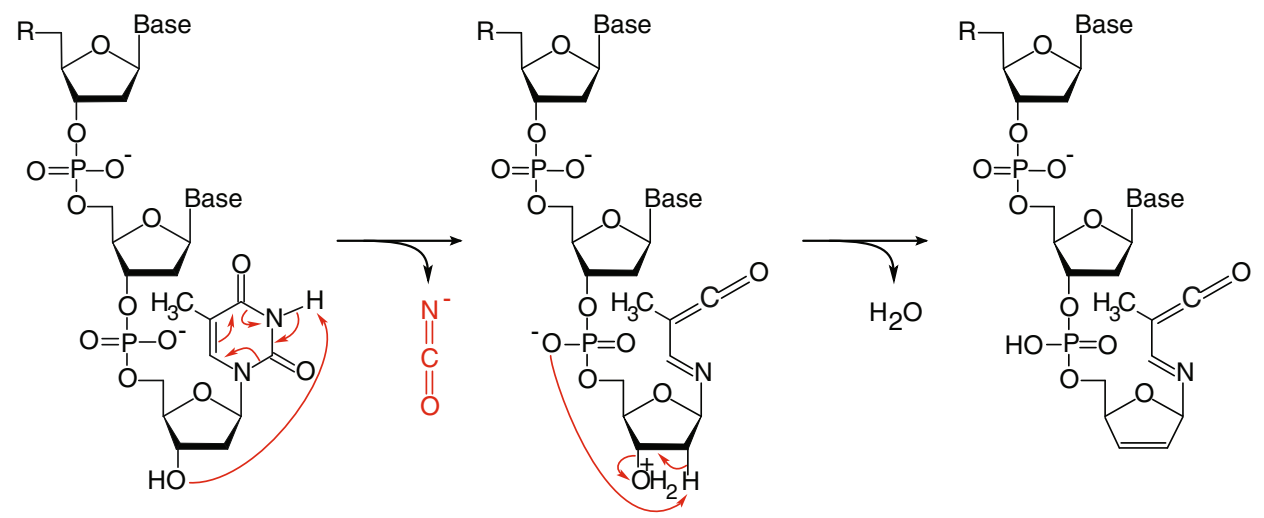

(b)
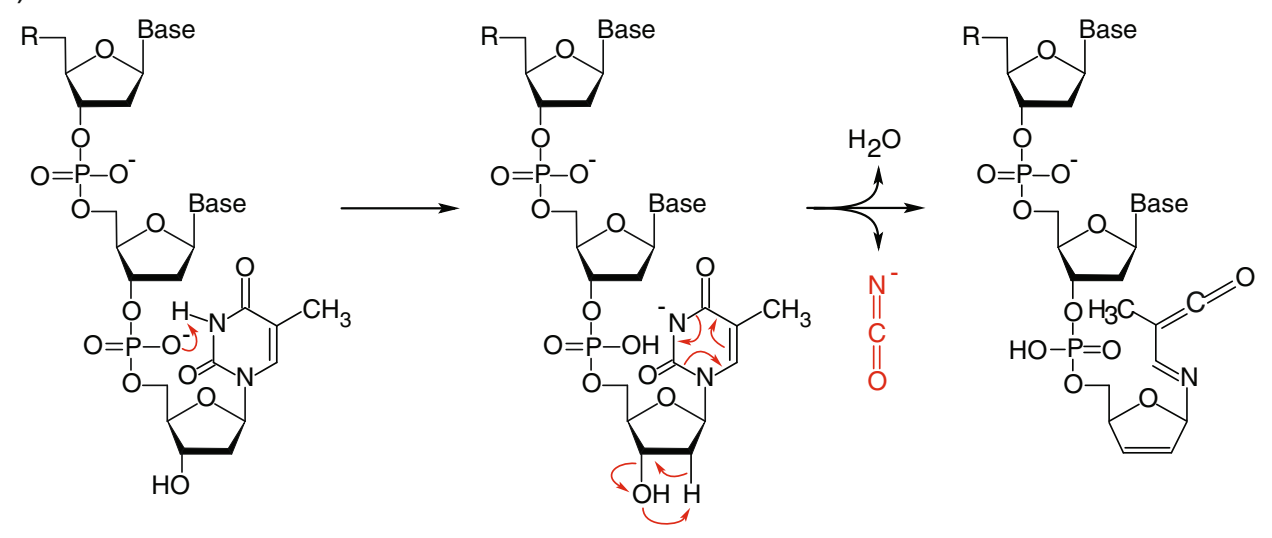

(c)
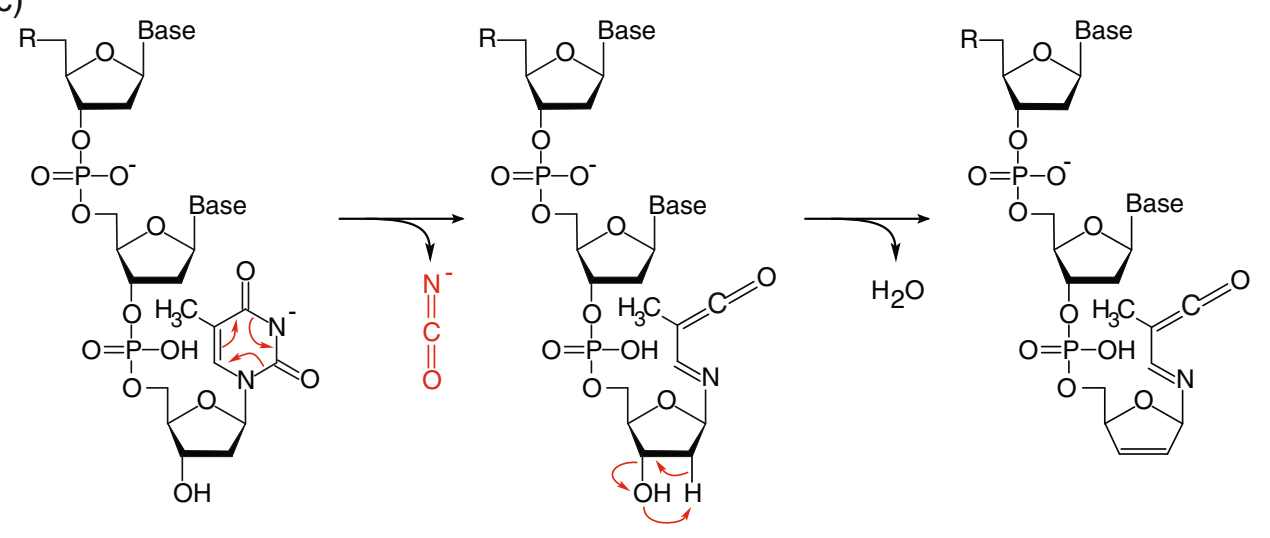

Scheme 1. Proposed fragmentation mechanisms for the release of $\mathrm{NCO}^{-}$upon $\mathrm{CID}$ of highly negatively charged oligonucleotides 
The first dissociation mechanism is depicted in Scheme 1a, where the terminal hydroxyl group plays a key role as it induces deprotonation of the N3 atom and undergoes subsequent water loss. The first deprotonation step in 1a could also explain the common generation of an

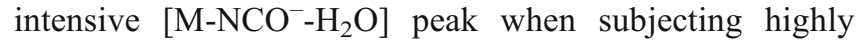
charged ONs to CID. This hypothesis was tested by investigating structurally modified CCGGTT that was lacking the $3^{\prime}-\mathrm{OH}$ group $\left(\mathrm{CCGGTT}^{\#}\right)$ and could thus not induce the crucial initial deprotonation of the N3 position. Yet, the product ion spectrum of $\left[\mathrm{CCGGTT}^{\#}\right]^{5-}$ was still

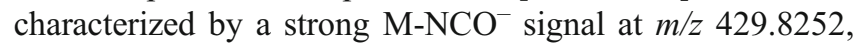
which in fact even constituted the base peak for this sequence (Supplemental Figure 3). Therefore, it is evident that the 3'-terminal $\mathrm{OH}$ group is not involved in the generation of the cyanate anion. However, the lack of any peaks corresponding to water loss proves that the hydroxyl group is the exclusive source of $\mathrm{H}_{2} \mathrm{O}$ elimination.

In pathway $1 \mathrm{~b}$, the reaction cascade is initiated by a proton transfer reaction from the $\mathrm{N} 3$ position of the terminal thymine nucleobase to the adjacent phosphate group. Deprotonation of the terminal $\mathrm{T}$ subsequently triggers the RDA reaction, which results in $\mathrm{NCO}^{-}$release and additional water loss. To assess if the phosphate backbone participates in the formation of $\mathrm{M}$ $\mathrm{NCO}^{-}$ions, the fully methylphosphonate (MP)-modified oligonucleotide (MP1) $C^{*} C^{*} G^{*} G^{*} T * T(*=$ MP modification) was subjected to CID. As the MP groups do not longer provide a suitable deprotonation site within the sequence, only the triply negatively charged precursor ion was formed. Hence, the three negative charges most probably reside on the nucleobases in an evenly distributed manner. According to the proposed mechanism $1 \mathrm{~b}$, the terminal phosphate group deprotonates the $\mathrm{N} 3$ position of the adjacent thymine and by that initiates the decomposition thereof. Thus, inhibition of this step is expected to completely block $\mathrm{NCO}^{-}$release. However, a small signal

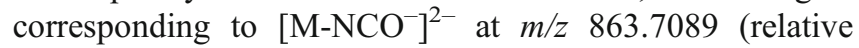
intensity $0.96 \%$ ) is still detected in the product ion spectrum of $C^{*} C^{*} G^{*} G^{*} T^{*} T$ (Figure 3). Even though the signal for cyanate release is rather low, it suggests that a phosphate group is not a crucial prerequisite for the $\mathrm{NCO}^{-}$dissociation channel. To further evaluate if $\mathrm{NCO}^{-}$loss could to a certain degree be explained by pathway $1 \mathrm{~b}$, the partially MP-modified sequence $\left[C^{*} C^{*} G^{*} G^{*} T T\right]^{3-}$ (MP2), which exhibits an ultimate native $\mathrm{PO}_{4}$-group, has also been investigated by CID. Owing to the low pKa of the phosphate group, one negative charge must definitely be located at this position and is thus able to abstract the N3 proton from T. According to mechanism $1 \mathrm{~b}$, this would consequently result in an at least slightly increased $\mathrm{M}-\mathrm{NCO}^{-}$ signal.

However, the product ion spectrum of the triply negatively charged MP2 precursor ion did not exhibit a stronger

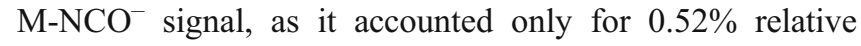
intensity and was thereby even lower than for the completely modified sequence MP1.

Interestingly, the quadruply charged precursor ion of MP2 generated a $\mathrm{M}-\mathrm{NCO}^{-}$peak of $6 \%$ (data not shown).
When considering the structure it is apparent that in addition to the negatively charged terminal phosphate group, the remaining three charges are most likely distributed similarly as in MP1. However, now the oligonucleotide experiences higher Coulombic repulsion and, hence, the terminal thymines' ability to induce backbone cleavage, as stated by Monn and Schürch [12], is probably slightly compromised, resulting in an increased ratio of $\mathrm{NCO}^{-}$release.

Still, at this point, the possibility that the phosphate group somewhat participates in the process of $\mathrm{NCO}^{-}$loss cannot be dismissed completely, as the weak signal of cyanate release for triply charged MP2 could also be attributable to the mere lack of a sufficiently high charge state. However, the hypothesis that the terminal phosphate oxygen is exclusively responsible for the initiation of cyanate release is not supported by the data and was thus rejected.

Consequently, fragmentation mechanism 1c is proposed to constitute the main pathway upon which a cyanate anion is released. It is independent of any other structural unit in the $\mathrm{ON}$ and the release of $\mathrm{NCO}^{-}$is triggered by initial deprotonation of the thymine N3, suggesting that a negative charge in a fully deprotonated oligonucleotide may reside on a nucleobase for a certain period of time. Since the N3bound proton in $\mathrm{T}$ is known to be more acidic than other potential deprotonation sites of the DNA nucleobases, proton abstraction at this position is most likely [41]. As the pathway is independent of the ON backbone, structural alterations thereof are not supposed to completely inhibit the formation of $\mathrm{NCO}^{-}$, which agrees well with the findings of CID of MP1 and MP2. Even though the lack of deprotonated phosphate groups compromises the oligonucleotides ability to adopt high charge levels, loss of a cyanate anion was observed for the triply negatively charged sequences and a considerable increase was detected as soon as the 4-fold negatively charged precursor ions of MP2 were subjected to CID.

Additional evidence for mechanism 1c was obtained by analyzing the single-stage mass spectra of the investigated sequences. Most mass spectra not only showed signals of the differently charged precursor ions, but some of them already exhibited a $\mathrm{M}-\mathrm{NCO}^{-}$peak as a result of in-source decay, such as the sequences GATCGT (\#1), TCGTCA (\#4), AGAGCT (\#6), and CGTAGTT (\#14). This observation strongly supports the theory that initial deprotonation of the terminal thymine, already taking place during the ionization process, automatically triggers spontaneous cyanate release by an RDA pathway if the Coulombic repulsion in the $\mathrm{ON}$ is sufficiently large.

\section{$\mathrm{NCO}^{-}$Loss from Oligoribonucleotides}

In literature, the reported fragmentation patterns of isolated thymine and uracil are very similar, especially with respect to the loss of isocyanic acid. Thus, fragmentation of highly charged RNA hexamers was also expected to yield cyanate loss, if a terminal uracil was present. The six investigated 

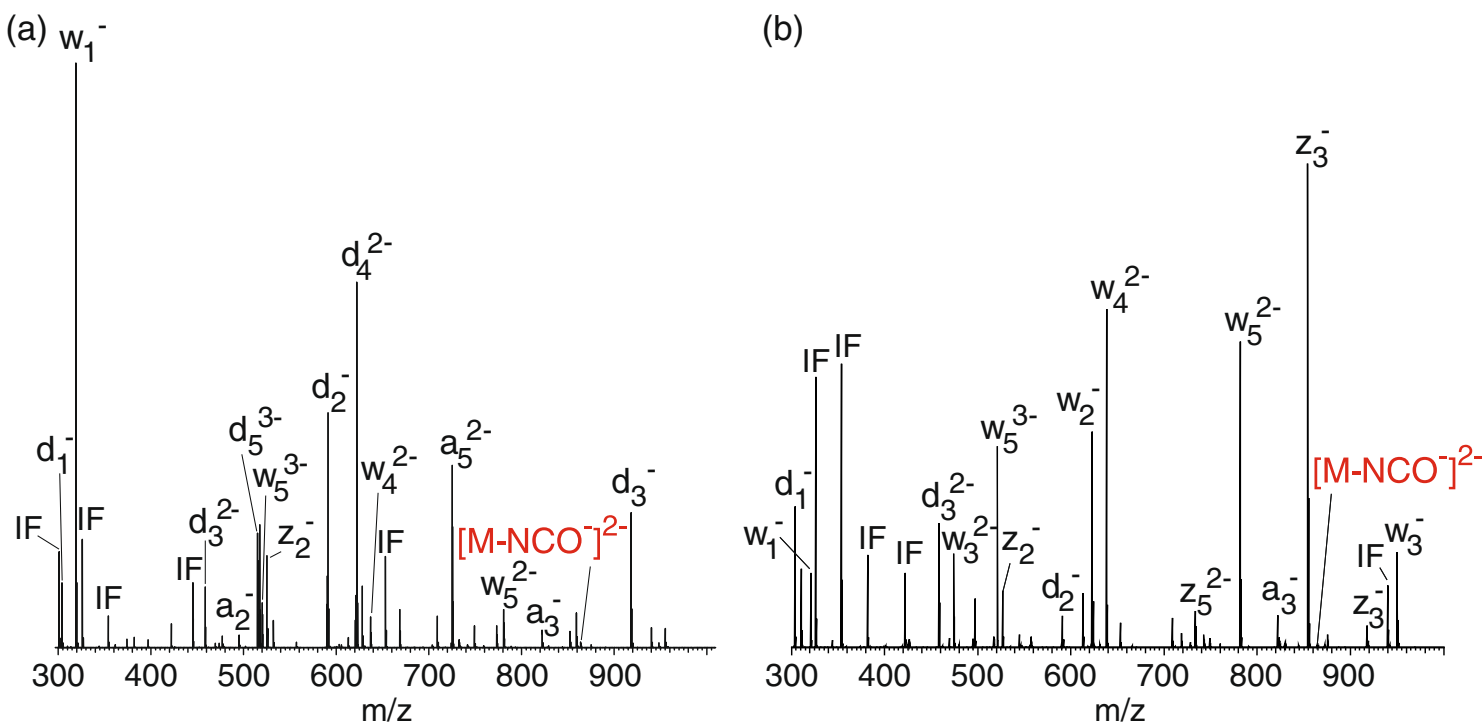

Figure 3. $M S^{2}$ spectra of $\left[C^{*} C^{*} G^{*} G^{*} T^{*} T\right]^{3-}$ and $\left[C^{*} C^{*} G^{*} G^{*} T\right]^{3-}$ exhibiting a $M-N C O^{-}$peak of $0.96 \%(m / z ~ 863.7089)$ and $0.52 \%$ $(\mathrm{m} / \mathrm{z}$ 864.6964), respectively. (IF = internal fragment) [RCE: (a) 15\%, (b) 20\%]

RNA sequences are displayed in Table 1 and all exhibit either a terminal $\mathrm{U}$ or $\mathrm{C}$. In general, the observations regarding cyanate abstraction are consistent with the results obtained for the DNA ONs in that the sequences exhibiting a

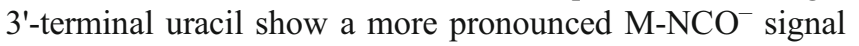
than those with a 5 '-terminal $\mathrm{U}$ or a terminal $\mathrm{C}$.

In fact, cyanate loss even constituted the base peak for all four sequences comprising a 3'-terminal uracil (\#23-\#26) and widely inhibited the generation of RNA typical backbone fragments, such as c- and y-ions (Figure 4a). However, despite of an intensive ${\mathrm{M}-\mathrm{NCO}^{-}}^{-}$peak in the product ion spectrum of GAUCGU, only a very low signal of a $\left[\mathrm{M}-\mathrm{NCO}^{-}-\mathrm{H}_{2} \mathrm{O}\right]$ fragment was detected. In general, concomitant water loss was an extremely minor event observed throughout fragmentation of the RNA hexamers and never accounted for more than $1 \%$ relative intensity. Therefore, the 2'-hydroxyl group, which constitutes the main structural difference between the DNA and RNA oligonucleotides, has to interfere with the elimination of $\mathrm{H}_{2} \mathrm{O}$.

Consequently, the 2'-proton is proposed to be involved in the process of water loss rather than the 4'-proton (Scheme 1), as the additional 2'-OH group in RNA most likely compromises facile proton abstraction at this position. Furthermore, the red marked product ions generated upon $\mathrm{MS}^{3}$ of [GAUCGU-NCO $]^{-4}$ confirm that as for DNA, cyanate loss exclusively occurs from the 3 '-terminal uracil and not from an internal position (Figure 4b).

\section{Subsequent Loss of a Metaphosphate Anion in DNA}

Another intriguing observation when fragmenting the RNA hexamers was the very low signal for metaphosphate $\left(\mathrm{PO}_{3}{ }^{-}\right)$ loss $(<1 \%$ rel. int.), which has always been observed
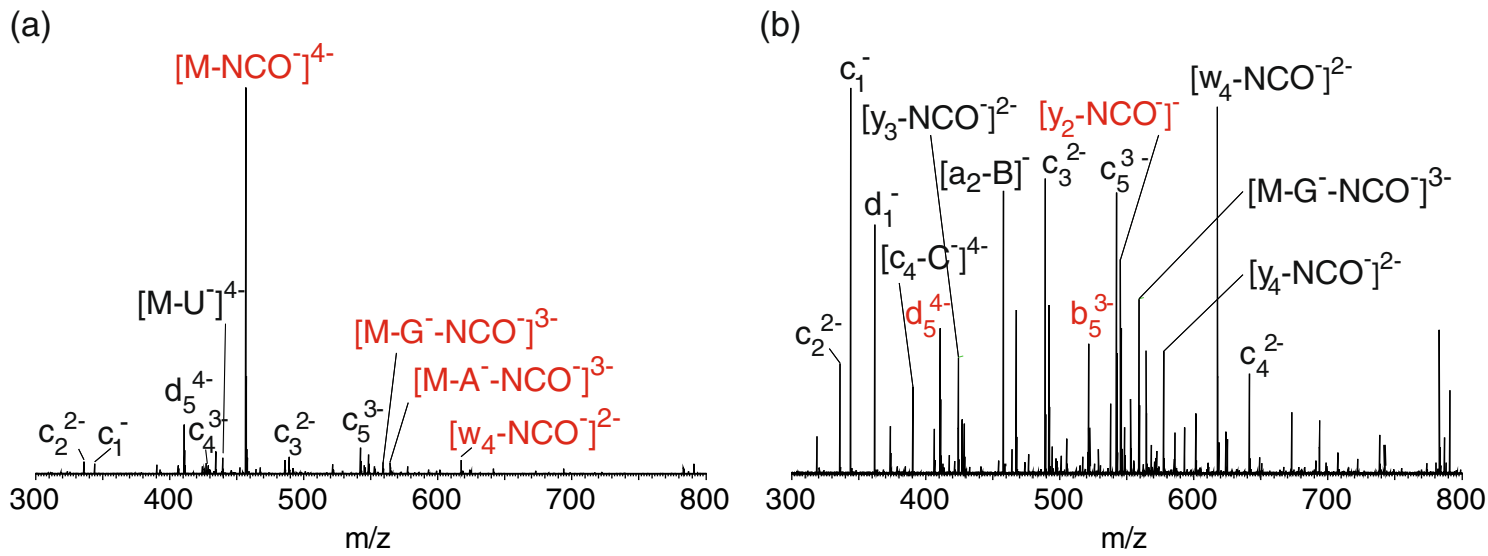

Figure 4. $\mathrm{MS}^{2}$ (a) and $\mathrm{MS}^{3}$ (b) spectra of GAUCGU demonstrating that oligoribonucleotides follow the same trend of prominent $\mathrm{NCO}^{-}$loss from terminal pyrimidines as DNA, when dissociating highly charged precursor ions. [RCE: (a) 30\%, (b) $18 \%]$ 
extensively in combination with release of $\mathrm{NCO}^{-}$and water for the DNA sequences, particularly in $\mathrm{MS}^{3}$ experiments of

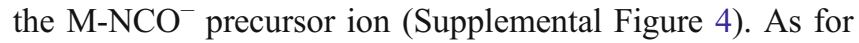
the abstraction of cyanate, loss of a metaphosphate anion represents a new dissociation channel for oligonucleotides and, to the best of our knowledge, has not been reported in literature so far.

Since additional abstraction of a sugar unit was not observed, loss of $\mathrm{PO}_{3}{ }^{-}$must be the result of an "excision" process rather than of backbone cleavage. The option that the terminal sugar moiety was only noncovalently attached to the remaining ON structure could be rejected, as $\mathrm{MS}^{3}$

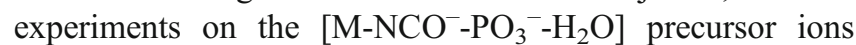
$(\mathrm{m} / \mathrm{z}$ 546.1088) of CCGGTT (\#9) generated backbone fragments still exhibiting the terminal sugar and [Base$\mathrm{NCO}^{-}$] moiety.

Comparing the relative intensities of the $\left[\mathrm{M}-\mathrm{NCO}^{-}-\mathrm{PO}_{3}^{-}-\right.$ $\mathrm{H}_{2} \mathrm{O}$ ] signals of the different investigated ONs, it is apparent that the charge level dependence of cyanate loss from thymine is also observed for the excision of the metaphosphate anion (Supplemental Table 1). For example, for GATCGT (\#1) metaphosphate loss accounted for 30.5\% when the CL was $100 \%$ but gradually decreased to $0.02 \%$ and $0 \%$ for the reduced charge levels of $80 \%$ and $60 \%$, respectively. The same trend was observed for longer sequences such as \#14 (7-mer) and \#20 (12-mer). Compound \#16 (8-mer) constitutes the only exception in the series, as $\mathrm{NCO}^{-}$release was more intensive for the $\mathrm{CL}$ of $85.7 \%$ than for $100 \%$ and, consequently, this also translates into a higher signal for metaphosphate loss for a CL of $85.7 \%$ in comparison to a fully deprotonated backbone.

Since successful isolation of a maximum charged precursor ion is strongly linked to the chain length of the corresponding $\mathrm{ON}$, the intensity of metaphosphate excision is inverse proportional to the length of the oligonucleotide and agrees well with the results obtained for $\mathrm{NCO}^{-}$loss. Hence, it is likely that the loss of $\mathrm{PO}_{3}{ }^{-}$also represents a form of charge-reduction to further relief Coulombic strain within the molecule. Owing to the strong co-occurrence of $\mathrm{PO}_{3}{ }^{-}$ loss with the release of $\mathrm{NCO}^{-}$and $\mathrm{H}_{2} \mathrm{O}$, the terminal position is likely to play a key role in this dissociation pathway as well.

To unambiguously confirm the terminal phosphate group as the source of metaphosphate excision, CCGGTT comprising a phosphorothioate group at the ultimate position was subjected to CID (CCGGTpsT). While cyanate abstraction constituted the base peak in the product ion spectrum of [CCGGTpsT] $]^{5-}$, [M-NCO- $\left.-\mathrm{PO}_{2} \mathrm{~S}^{-}-\mathrm{H}_{2} \mathrm{O}\right]^{3-}$ at $\mathrm{m} / z 546.1088$ exhibited the second most intensive peak with a relative intensity of around $80 \%$ (Figure 5). The lack of any [M$\left.\mathrm{NCO}^{-}-\mathrm{PO}_{3}{ }^{-}-\mathrm{H}_{2} \mathrm{O}\right]$ signal verifies that exclusively the ultimate phosphate group is involved in this fragmentation pathway.

Since the excision of a $\mathrm{PO}_{3}{ }^{-}$has not been mechanistically investigated so far, two potential fragmentation pathways were proposed (Scheme 2) that could explain the release of

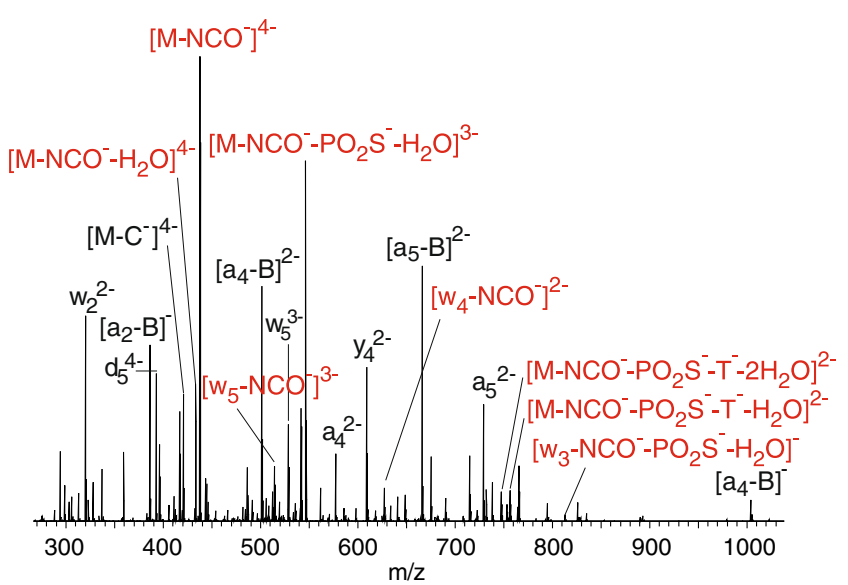

Figure 5. Product ion spectrum of [CCGGTpsT] $]^{5-}$ giving evidence for the subsequent excision of the ultimate phosphorothioate group after loss of a cyanate anion and water [RCE: 15\%]

the terminal metaphosphate group from the $\mathrm{M}-\mathrm{NCO}^{-}$ precursor. $\mathrm{As}_{\mathrm{PO}_{3}}{ }^{-}$loss is only observed in combination with the abstraction of cyanate and water, prior elimination of these subunits is suggested to be a prerequisite for the subsequent release of $\mathrm{PO}_{3}^{-}$and was thus accounted for in the dissociation mechanisms.

The first mechanism is shown in Scheme $2 \mathrm{a}$ and comprises a total of three subsequent steps that finally result in the release of a metaphosphate anion. First, the deprotonated oxygen of the penultimate phosphate group attacks the ketene structure, generating a covalent $\mathrm{C}-\mathrm{O}$ bond. Afterwards, the 2'-proton is abstracted to initiate 3'$\mathrm{C}-\mathrm{O}$ bond cleavage, but not the 4'-proton, and in that resembles the pathway for water loss. As for the abstraction of $\mathrm{H}_{2} \mathrm{O}$, extensive metaphosphate excision was an exclusive observation for highly charged DNA sequences, whereas RNA underwent a negligible amount of metaphosphate loss. This indicates that the 2'-position is involved in the process of $\mathrm{PO}_{3}{ }^{-}$loss. In order to find additional evidence to confirm the proposed fragmentation mechanism 2a, highly charged homoDNA sequences were investigated for their ability of cyanate and metaphosphate loss. HomoDNA is structurally altered DNA that exhibits a hexose sugar unit instead of a pentose (Supplemental Figure 5). According to Schemes 1 and 2, homoDNA is able to undergo loss of $\mathrm{NCO}^{-}$, whereas the loss of $\mathrm{PO}_{3}{ }^{-}$and water is impeded by the hexose sugar unit, as abstraction of the 2'-proton neither induces water loss nor cleavage of the $4^{\prime}-\mathrm{C}-\mathrm{O}$ bond (3'-C-O for DNA).

The following highly charged homoDNA sequences (CL $100 \%)$ were investigated by MS/MS: ccggtt (H1) and ttccgg (H2) as well as the mixmer cacGT (HX) (lower case nucleobases indicate homoDNA-modified building blocks). The product ion spectra of $\mathrm{H} 1$ and $\mathrm{H} 2$ are both characterized by extensive $\mathrm{NCO}^{-}$loss (Supplemental Figure 6), accompanied by additional base loss signals, which is in agreement with a recently published study [42]. In general, 
(a)

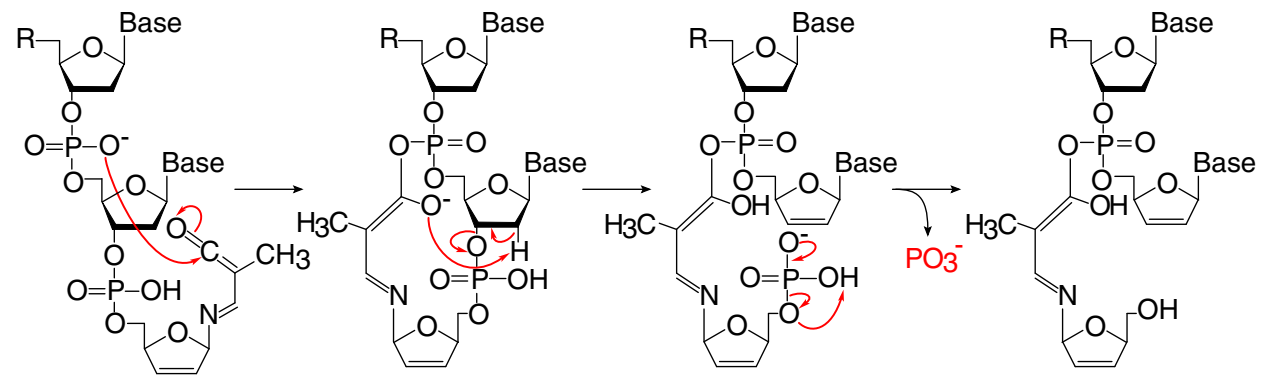

(b)
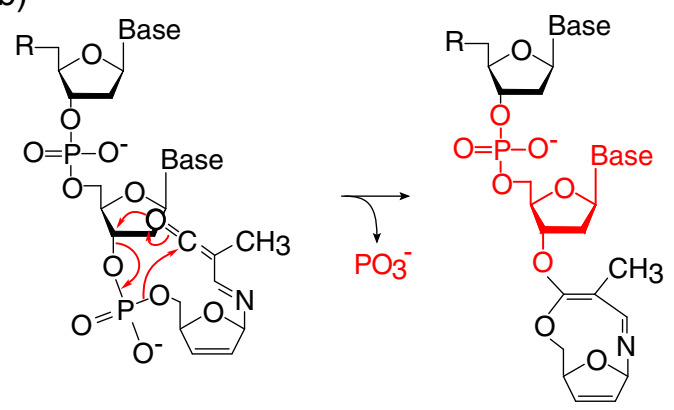

Scheme 2. Postulated mechanisms for metaphosphate excision as subsequent reaction to $\mathrm{NCO}^{-}$and water loss

release of cyanate seems to be even more prevalent for homoDNA than for unmodified DNA. The presence of two terminal pyrimidine bases even resulted in the detection of double $\mathrm{NCO}^{-}$loss at $\mathrm{m} / \mathrm{z} 592.4633$, which has never been observed for other sequences, such as TGCTGC (\#7) or CCGGTT (\#9). Since neither H1 nor H2 yielded any peaks corresponding to loss of water or metaphosphate though, validity of the mechanisms 1c (Scheme 1) and 2a (Scheme 2) is highly probable. Even $\mathrm{MS}^{3}$ of the corresponding $\mathrm{M}-\mathrm{NCO}^{-}$fragment resulted in further base loss only, with no evidence for water or metaphosphate abstraction (Supplemental Figure 6).

Additional confirmation for this hypothesis was obtained by analysis of the mixed DNA-homoDNA pentamer cacGT, which not only showed loss of $\mathrm{NCO}^{-}$, but also exhibited elimination of water and metaphosphate in $\mathrm{MS}^{2}$ and $\mathrm{MS}^{3}$ experiments (Supplemental Figure 7). Consequently, the 2'position is very likely to be involved in the process of water loss and metaphosphate excision as postulated in Schemes 1c and 2a. Even though the latter pathway involves a series of different dissociation steps, including a final rearrangement for the metaphosphate release, the involvement of the 2'-position at least partially explains why highly charged RNA and homoDNA do not exhibit loss of water and metaphosphate.

Mechanism 2b was suggested by a reviewer and involves a single, concerted reaction cascade starting with an attack of the 3'-C-O bond by the ketene oxygen. As this pathway involves considerably fewer dissociation steps, it certainly represents a viable option for the excision of a $\mathrm{PO}_{3}^{-}$moiety. Scheme $2 \mathrm{~b}$ does not explain why metaphosphate loss is not observed upon CID of highly charged RNA and homoDNA, although it is theoretically applicable to both forms of nucleic acids. When analyzing the $\mathrm{MS}^{3}$ data of the $\left[\mathrm{M}-\mathrm{NCO}^{-}-\mathrm{PO}_{3}{ }^{-}\right.$ $\mathrm{H}_{2} \mathrm{O}$ ] precursor ion of CCGGTT (\#9) and GATCGT (\#1), neither rejection nor confirmation of one of these mechanisms was feasible as conclusive fragments, such as $\mathrm{d}_{4} / \mathrm{d}_{5^{-}}$or $\mathrm{c}_{4} / \mathrm{c}_{5^{-}}$-ions or small $3^{\prime}$-terminal fragments lacking the $\mathrm{NCO}^{-}, \mathrm{PO}_{3}^{-}$, and $\mathrm{H}_{2} \mathrm{O}$ moieties were not generated upon fragmentation (Supplemental Figure 8). However, the peak at $\mathrm{m} / z 321.0486$ could be a hint that the proposed product of mechanism $2 \mathrm{~b}$ at least partially reflects the structure of the $\left[\mathrm{M}-\mathrm{NCO}^{-}-\mathrm{PO}_{3}{ }^{-} \mathrm{H}_{2} \mathrm{O}\right]$ fragment. The mass is a perfect match with a $\mathrm{w}_{1}$-ion, which, because of $\mathrm{NCO}^{-}$release from the terminal thymine base, cannot be generated. Considering the final structure in Scheme $2 b$, a "pseudo- $\mathrm{w}_{1}$-ion" could be generated by cleavage of the $3^{\prime}-\mathrm{C}-\mathrm{O}$ bond at the $\mathrm{w}_{2^{-}}$as well as the former $b_{5}$-ion position (highlighted in red). Accordingly, the $\mathrm{MS}^{3}$ spectrum of GATCGT should exhibit such a

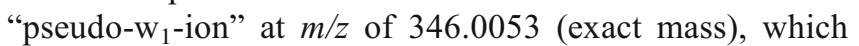
was not detected and, hence, contradicts this theory.

In general, the $\mathrm{S} / \mathrm{N}$ ratio decreased considerably at the $\mathrm{MS}^{3}$ stage, so that very low abundant marker ions might not have been detected. Unfortunately, the low overall signal intensity rendered the analysis of the $\left[\mathrm{M}-\mathrm{NCO}^{-}-\mathrm{PO}_{3}{ }^{-}-\mathrm{H}_{2} \mathrm{O}\right]$ fragment of ONs other than $\# 9$ and $\# 1$, which exhibited the most intensive signal for metaphosphate loss, impossible.

Summarizing, it remains ambiguous which pathway $\mathrm{PO}_{3}{ }^{-}$-excision is precisely following and why the loss of water seems to be a prerequisite for the excision of $\mathrm{PO}_{3}{ }^{-}$. It is also possible that alternative mechanisms to the two proposed in Scheme 2 apply or that even a combination of 
different fragmentation pathways lead to the observed complex phenomenon of metaphosphate excision.

\section{Conclusion}

In this study, new insights into the fragmentation of highly charged ONs were gained. It was demonstrated that loss of a cyanate anion not only constitutes a prominent dissociation channel for isolated nucleobases, nucleosides, and nucleotides but also for longer oligonucleotides exhibiting a high charge level $(>90 \%)$ as well as a terminal pyrimidine nucleobase. In the case of DNA sequences, $\mathrm{NCO}^{-}$release was commonly accompanied by elimination of water and the so far unreported subsequent excision of a metaphosphate anion $\left(\mathrm{PO}_{3}^{-}\right)$. To gain deeper insight into the underlying fragmentation mechanism an array of different DNA and RNA sequences was investigated by MS/MS, resulting in three potential mechanisms for the loss of $\mathrm{NCO}^{-}$and water as well as two mechanisms accounting for consecutive metaphosphate excision. By analyzing modified oligonucleotides comprising specific structural alterations that either inactivate a particular reaction step or result in a mass shift of the generated fragment ion, the underlying mechanisms for the formation of $\mathrm{M}-\mathrm{NCO}^{-}$and $\mathrm{M}-\mathrm{NCO}^{-}-\mathrm{PO}_{3}{ }^{-}$ions were reconstructed step-by-step. It was shown that the approach of strategic incorporation of modification sites is very well suited to unravel so far unidentified dissociation pathways and to rationalize the generation of specific product ions.

\section{Acknowledgments}

The authors thank C. Désiron and C. J. Leumann for providing the homoDNA sequences. Further, the authors gratefully acknowledge financial support of this work by the Swiss National Science Foundation (grant \#200020_140628).

\section{References}

1. Gross, J., Hillenkamp, F., Wan, K.X., Gross, M.L.: Metastable decay of negatively charged oligodeoxynucleotides analyzed with ultraviolet matrix-assisted laser desorption/ionization post-source decay and deuterium exchange. J. Am. Soc. Mass Spectrom. 12, 180-192 (2001)

2. McLuckey, S.A., Habibi-Goudarzi, S.: Decompositions of multiplycharged oligonucleotide anions. J. Am. Chem. Soc. 115, 12085-12095 (1993)

3. Wan, K.X., Gross, J., Hillenkamp, F., Gross, M.L.: Fragmentation mechanisms of oligodeoxynucleotides studied by H/D exchange and electrospray ionization tandem mass spectrometry. J. Am. Soc. Mass Spectrom. 12, 193-205 (2001)

4. Wang, Z., Wan, K.X., Ramanathan, R., Taylor, J.S., Gross, M.L.: Structure and fragmentation mechanisms of isomeric T-rich oligodeoxynucleotides: a comparison of four tandem mass spectrometric methods. J. Am. Soc. Mass Spectrom. 9, 683-691 (1998)

5. Schürch, S., Bernal-Mendez, E., Leumann, C.J.: Electrospray tandem mass spectrometry of mixed-sequence RNA/DNA oligonucleotides. J. Am. Soc. Mass Spectrom. 13, 936-945 (2002)

6. Tromp, J.M., Schürch, S.: Gas-phase dissociation of oligoribonucleotides and their analogs studied by electrospray ionization tandem mass spectrometry. J. Am. Soc. Mass Spectrom. 16, 12621268 (2005)
7. Andersen, T.E., Kirpekar, F., Haselmann, K.F.: RNA fragmentation in MALDI mass spectrometry studied by H/D-exchange: mechanisms of general applicability to nucleic acids. J. Am. Soc. Mass Spectrom. 17, 1353-1368 (2006)

8. Tromp, J.M., Schürch, S.: Electrospray ionization tandem mass spectrometry of biphenyl-modified oligo(deoxy)ribonucleotides. Rapid Commun. Mass Spectrom. 20, 2348-2354 (2006)

9. Keough, T., Baker, T.R., Dobson, R.L.M., Lacey, M.P., Riley, T.A., Hasselfield, J.A., Hesselberth, P.E.: Antisense DNA oligonucleotides. 2. The use of matrix-assisted laser desorption ionization mass-spectrometry for the sequence verification of methylphosphonate oligodeoxyribonucleotides. Rapid Commun. Mass Spectrom. 7, 195-200 (1993)

10. Bartlett, M.G., McCloskey, J.A., Manalili, S., Griffey, R.H.: The effect of backbone charge on the collision-induced dissociation of oligonucleotides. J. Mass Spectrom. 31, 1277-1283 (1996)

11. Wang, B.H., Hopkins, C.E., Belenky, A.B., Cohen, A.S.: Sequencing of modified oligonucleotides using in-source fragmentation and delayed pulsed ion extraction matrix-assisted laser desorption ionization time-offlight mass spectrometry. Int. J. Mass Spectrom. 169, 331-350 (1997)

12. Monn, S.T.M., Schürch, S.: New aspects of the fragmentation mechanisms of unmodified and methylphosphonate-modified oligonucleotides. J. Am. Soc. Mass Spectrom. 18, 984-990 (2007)

13. Nyakas, A., Stucki, S.R., Schürch, S.: Tandem mass spectrometry of modified and platinated oligoribonucleotides. J. Am. Soc. Mass Spectrom. 22, 875-887 (2011)

14. Wan, K.X., Gross, M.L.: Fragmentation mechanisms of oligodeoxynucleotides: effects of replacing phosphates with methylphosphonates and thymines with other bases in T-rich sequences. J. Am. Soc. Mass Spectrom. 12, 580-589 (2001)

15. Nyakas, A., Eymann, M., Schürch, S.: The influence of cisplatin on the gas-phase dissociation of oligonucleotides studied by electrospray ionization tandem mass spectrometry. J. Am. Soc. Mass Spectrom. 20, 792-804 (2009)

16. Rozenski, J.: Mongo oligonucleotide mass calculator. Available at: http://mods.rna.albany.edu/masspec/Mongo-Oligo. Accessed January 2014

17. Rozenski, J., McCloskey, J.A.: SOS: a simple interactive program for $\mathrm{ab}$ initio oligonucleotide sequencing by mass spectrometry. J. Am. Soc. Mass Spectrom. 13, 200-203 (2002)

18. Nyakas, A., Blum, L.C., Stucki, S.R., Reymond, J.-L., Schürch, S.: OMA and OPA software-supported mass spectra analysis of native and modified nucleic acids. J. Am. Soc. Mass Spectrom. 24, 249-256 (2013)

19. Yang, J., Leopold, P., Helmy, R., Parish, C., Arvary, B., Mao, B., Meng, F.: Design and application of an easy to use oligonucleotide mass calculation program. J. Am. Soc. Mass Spectrom. 24, 1315-1318 (2013)

20. Pan, S., Verhoeven, K., Lee, J.K.: Investigation of the initial fragmentation of oligodeoxynucleotides in a quadrupole ion trap: charge level-related base loss. J. Am. Soc. Mass Spectrom. 16, 18531865 (2005)

21. Huang, T.Y., Kharlamova, A., Liu, J., McLuckey, S.A.: Ion trap collision-induced dissociation of multiply deprotonated RNA: c/y-ions versus (a-B)/w-ions. J. Am. Soc. Mass Spectrom. 19, 1832-1840 (2008)

22. Rice, J.M., Dudek, G.O., Barber, M.: Mass spectra of nucleic acid derivatives-pyrimidines. J. Am. Chem. Soc. 87, 4569-4576 (1965)

23. Jochims, H.W., Schwell, M., Baumgartel, H., Leach, S.: Photoion mass spectrometry of adenine, thymine and uracil in the $6-22 \mathrm{eV}$ photon energy range. Chem. Phys. 314, 263-282 (2005)

24. Flosadóttir, H.D., Jónsson, H., Sigurdsson, S.T., Ingólfsson, O.: Experimental and theoretical study of the metastable decay of negatively charged nucleosides in the gas phase. Phys. Chem. Chem. Phys. 13, 15283-15290 (2011)

25. Almeida, D., Antunes, R., Martins, G., Eden, S., da Silva, F.F., Nunes, Y., Garcia, G., Limao-Vieira, P.: Electron transfer-induced fragmentation of thymine and uracil in atom-molecule collisions. Phys. Chem. Chem. Phys. 13, 15657-15665 (2011)

26. Imhoff, M., Deng, Z.W., Huels, M.A.: Identification of ion fragments produced from thymine and deuterated thymine by low energy ion impact in films and electron impact in the gas phase. Int. J. Mass Spectrom. 245, 68-77 (2005)

27. Nelson, C.C., McCloskey, J.A.: Collision-induced dissociation of uracil and its derivatives. J. Am. Soc. Mass Spectrom. 5, 339-349 (1994)

28. Cao, H., Wang, Y.: Collisionally activated dissociation of protonated 2'deoxycytidine, 2'-deoxyuridine, and their oxidatively damaged derivatives. J. Am. Soc. Mass Spectrom. 17, 1335-1341 (2006) 
29. Kamel, A.M., Munson, B.: Collisionally-induced dissociation of substituted pyrimidine antiviral agents: mechanisms of ion formation using gas phase hydrogen/deuterium exchange and electrospray ionization tandem mass spectrometry. J. Am. Soc. Mass Spectrom. 18, 1477-1492 (2007)

30. Bald, I., Flosadóttir, H.D., Ómarsson, B., Ingólfsson, O.: Metastable fragmentation of a thymidine-nucleotide and its components. Int. J. Mass Spectrom. 313, 15-20 (2012)

31. Arani, L.S., Mignon, P., Abdoul-Carime, H., Farizon, B., Farizon, M., Chermette, H.: DFT study of the fragmentation mechanism of uracil RNA base. Phys. Chem. Chem. Phys. 14, 9855-9870 (2012)

32. Guillaumont, S., Tortajada, J., Salpin, J.Y., Lamsabhi, A.M.: Experimental and computational study of the gas-phase interactions between lead(II) ions and two pyrimidic nucleobases: uracil and thymine. Int. J. Mass Spectrom. 243, 279-293 (2005)

33. Flosadóttir, H.D., Ómarsson, B., Bald, I., Ingólfsson, O.: Metastable decay of DNA components and their compositions - a perspective on the role of reactive electron scattering in radiation damage. Eur. Phys. J. D 66, 13 (2012)

34. Lamsabhi, A.M., Alcami, M., Mo, O., Yanez, M., Tortajada, J., Salpin, J.-Y.: Unimolecular reactivity of uracil- $\mathrm{Cu} 2(+)$ complexes in the gas phase. Chem. Phys. Chem. 8, 181-187 (2007)

35. Beach, D.G., Gabryelski, W.: Revisiting the reactivity of uracil during collision induced dissociation: tautomerism and charge-directed processes. J. Am. Soc. Mass Spectrom. 23, 858-868 (2012)

36. Improta, R., Scalmani, G., Barone, V.: Radical cations of DNA bases: some insights on structure and fragmentation patterns by density functional methods. Int. J. Mass Spectrom. 201, 321-336 (2000)
37. da Silva, F.F., Matias, C., Almeida, D., Garcia, G., Ingólfsson, O., Flosadóttir, H.D., Ómarsson, B., Ptasinska, S., Puschnigg, B., Scheier, P., Limao-Vieira, P., Denifl, S.: NCO, a key fragment upon dissociative electron attachment and electron transfer to pyrimidine bases: site selectivity for a slow decay process. J. Am. Soc. Mass Spectrom. 24, 1787-1797 (2013)

38. Ziehe, M., Grossmann, T.N., Seitz, O., Linscheid, M.W.: New aspects in fragmentation of peptide nucleic acids: comparison of positive and negative ions by electrospray ionization Fourier transform ion cyclotron resonance mass spectrometry. Rapid Commun. Mass Spectrom. 23, 1132-1138 (2009)

39. Bohringer, M., Roth, H.J., Hunziker, J., Gobel, M., Krishnan, R., Giger, A., Schweizer, B., Schreiber, J., Leumann, C., Eschenmoser, A.: Why pentose and not hexose nucleic-acids. 2. Preparation of oligonucleotides containing 2',3'-dideoxy-beta-d-glucopyranosyl building-blocks. Helv. Chim. Acta 75, 1416-1477 (1992)

40. Anusiewicz, W., Berdys-Kochanska, J., Czaplewski, C., Sobczyk, M., Daranowski, E.M., Skurski, P., Simons, J.: Charge loss in gas-phase multiply negatively charged oligonucleotides. J. Phys. Chem. A 109, 240-249 (2005)

41. Chandra, A.K., Nguyen, M.T., Uchimaru, T., Zeegers-Huyskens, T.: Protonation and deprotonation enthalpies of guanine and adenine and implications for the structure and energy of their complexes with water: comparison with uracil, thymine, and cytosine. J. Phys. Chem. A 103, 8853-8860 (1999)

42. Stucki, S.R., Desiron, C., Nyakas, A., Marti, S., Leumann, C.J., Schürch, S.: Gas-phase dissociation of homo-DNA oligonucleotides. J. Am. Soc. Mass Spectrom. 24, 1997-2006 (2013) 